\title{
ADUBAÇÃO DE SOQUEIRA DE CANA-DE-AÇÚCAR COM SOLUÇÕES DE CARBONATO/BICARBONATO DE AMÔNIO EM MISTURA COM SAIS DE POTÁSSIO E DE FÓSFORO
}

\author{
Fábio Alvares de Oliveira ${ }^{1,5 *}$; Alberto Carlos de Campos Bernardi'; Valdomiro Corrêa de \\ Bittencourt ${ }^{3,5}$; Quirino Augusto de Camargo Carmello ${ }^{4}$ \\ ${ }^{1}$ Pós-Graduando do Depto. de Solos e Nutrição de Plantas - ESALQ/USP. \\ ${ }^{2}$ Embrapa Solos - CEP: 22460-000 - Rio de Janeiro, RJ. \\ ${ }^{3}$ Depto. de Ciências Exatas - ESALQ/USP, C.P. 9 - CEP: 13418-900 - Piracicaba, SP. \\ ${ }^{4}$ Depto. de Solos e Nutrição de Plantas - ESALQ/USP. \\ ${ }^{5}$ Bolsista do CNPq. \\ *e-mail: faolivei@carpa.ciagri.usp.br
}

RESUMO: Comparam-se as eficiências de soluções de aquamônia e de carbonato/bicarbonato de amônio contendo sais de $\mathrm{K}$ e de $\mathrm{P}$ quanto à produção de material seco da parte aérea e ao aproveitamento do $\mathrm{N}$ aplicado como fertilizante por cana-de-açúcar. Soqueiras de cana-de-açúcar da variedade "RB72454" foram transplantadas para vasos de $100 \mathrm{dm}^{3}$ de terra e cultivadas por noventa dias. $O$ delineamento experimental utilizado foi em esquema fatorial $2 \times 3$ inteiramente casualizado, com 4 repetições. Os tratamentos consistiram no fornecimento de fontes de $\mathrm{N} \mathrm{em}$ combinações ou não com KCl e $\mathrm{NH}_{4} \mathrm{H}_{2} \mathrm{PO}_{4}$. Os nutrientes $\mathrm{P}$ e K não incluídos em cada tratamento foram aplicados em outro ponto, à mesma distância e profundidade das soqueiras que as soluções de tratamento, para assegurar a igualdade das quantidades de $N, P$ e $K$ aplicadas a todas as parcelas. Avaliaram-se a produção de material seco da parte aérea, a extração total de $\mathrm{N}$ e a recuperação do $\mathrm{N}$ do fertilizante. Considerou-se, para este último parâmetro, a extração do $\mathrm{N}$ do solo pelas soqueiras de unidades que receberam somente sais de $\mathrm{K}$ e de $\mathrm{P}$. As soluções com carbonatol bicarbonato de amônio resultaram em maiores produções de material seco da parte aérea que as de aquamônia, porém, não diferiram quanto à extração total de $\mathrm{N}$ e ao $\mathrm{N}$ recuperado do fertilizante. A adição de $\mathrm{KCl}$ e $\mathrm{NH}_{4} \mathrm{H}_{2} \mathrm{PO}_{4}$ às soluções de $\mathrm{N}$ não interferiram na extração e na eficiência de recuperação do $\mathrm{N}$ aplicado, para as relações $\mathrm{N}: \mathrm{K}$ e $\mathrm{N}: \mathrm{P}: \mathrm{K}$ avaliadas.

Palavras-chave: adubo não convencional, fertilizante fluido, nitrogênio

\section{SUGARCANE RATOON FERTILIZATION WITH AMMONIUM CARBONATE/BICARBONATE SOLUTIONS MIXED WITH POTASSIUM AND PHOSPHORUS SALTS}

ABSTRACT: The efficiencies of aqua ammonia and ammonium carbonate/bicarbonate solutions mixed with $\mathrm{K}$ and $\mathrm{P}$ salts were compared to shoot dry matter yield and the profit of $\mathrm{N}$ applied from fertilizers by sugarcane. Sugarcane ratoons, cultivar "RB72454", were transplanted to $100 \mathrm{dm}^{3}$ soil pots and were grown for ninety days. The experimental design adopted was a 2 × 3 completely randomized factorial, with 4 replications. Treatments consisted of supplying $\mathrm{N}$ sources mixed or not with $\mathrm{KCl}$ and $\mathrm{NH}_{4} \mathrm{H}_{2} \mathrm{PO}_{4}$. $\mathrm{P}$ and $\mathrm{K}$ nutrients not included in each treatment were applied at another point, but at the same distance and depth from ratoons than the treatment solutions, to assure the equality of the rates of $N, P$ and $K$ applied to all treatments. Shoot dry matter yield, total $\mathrm{N}$ uptake and $\mathrm{N}$ recover from the fertilizer solutions were evaluated. This last parameter, was considered as soil $\mathbf{N}$ uptake by ratoons of plots, which received only $K$ and $P$ salts. The ammonium carbonate/bicarbonate solutions lead to greater shoot dry matter yield than the aqua ammonia, but they did not differ in respect of the total $\mathrm{N}$ uptake and $\mathrm{N}$ recover from the fertilizers solutions. The $\mathrm{KCl}$ and $\mathrm{NH}_{4} \mathrm{H}_{2} \mathrm{PO}_{4}$ inclusion to $\mathrm{N}$ solutions did not affect the total $\mathrm{N}$ uptake and $\mathrm{N}$ recover efficiency, to the evaluated $\mathrm{N}: \mathrm{K}$ and $\mathrm{N}: \mathrm{P}: \mathrm{K}$ ratios.

Key words: non conventional fertilizer, fluid fertilizer, nitrogen

\section{INTRODUÇÃO}

A produção do carbonato/bicarbonato de amônio é uma alternativa para o aproveitamento do $\mathrm{CO}_{2}$ gerado na fermentação alcoólica. Através de uma reação de carbonatação da aquamônia, esse produto pode ser obtido e utilizado como fertilizante, reduzindo o gasto energético do sistema alcooleiro, representado pelo desperdício do $\mathrm{CO}_{2}$ (Fuzato et al., 1988). Este fertilizante teve 
demonstrado seu potencial de utilização, como fonte de nitrogênio, na cultura do arroz na China (Li \& Chen, 1980). Por ser um fertilizante amoniacal, apresenta o mesmo tipo de comportamento no solo deste grupo de fertilizantes e requer, portanto, as mesmas recomendações e restrições de utilização.

As perdas por volatilização da amônia em solos ácidos, quando utiliza-se uréia ou carbonato/bicarbonato de amônio, podem ser reduzidas pela utilização de aditivos químicos junto ao fertilizante. Segundo Terman (1979), a ação desses aditivos ocorre pela geração de ácidos que evitam a excessiva elevação do $\mathrm{pH}$ no local de aplicação. Esse processo, geralmente, é obtido pelo deslocamento dos íons $\mathrm{Al}^{3+}$ do complexo de troca por cátions presentes nos aditivos, favorecendo a precipitação do $\mathrm{Al}^{3+}$ na forma de hidróxido, aumentando, assim, a atividade de íons $\mathrm{H}^{+}$.

Outro efeito é o da precipitação dos cátions $\mathrm{Ca}^{2+}$ e $\mathrm{Mg}^{2+}$ com $\mathrm{o}$ carbonato proveniente da hidrólise da uréia ou carbonato/bicarbonato de amônio, em valores de $\mathrm{pH}$ acima de 7 , diminuindo o valor máximo de $\mathrm{pH}$ atingido e liberando sítios de adsorção para o cátion amônio (Du Plessis \& Kroontje, 1966; Fenn \& Miyamoto, 1981). Em função do $\mathrm{pH}$ exigido para a precipitação dos cátions divalentes, a adsorção do $\mathrm{NH}_{4}^{+}$resultante é mais efetiva em solos alcalinos. No caso de solos ácidos, a dissolução de fontes nitrogenadas como a uréia e o carbonato/bicarbonato de amônio pode elevar o pH acima de 7 , no ponto de aplicação. O efeito da precipitação de

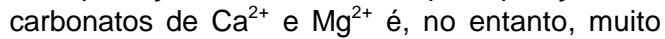
efêmero, uma vez que o pH do solo retorna rapidamente à valores ácidos. Contudo, essa complexação parcial do carbonato promove uma redução inicial das perdas de amônia por volatilização, refletindo numa curva menos acentuada de perdas em função do tempo decorrido da aplicação e uma perda total acumulada inferior (Fenn et al., 1981).

Com base nesse efeito, sais de $\mathrm{Ca}^{2+} \mathrm{e}$ $\mathrm{Mg}^{2+}$ têm sido aplicados juntamente com a uréia para reduzir as perdas de amônia por volatilização em solos ácidos, mantendo $0 \mathrm{NH}_{4}{ }^{+}$ em solução, formando pares iônicos com os ânions $\mathrm{Cl}^{-}$e $\mathrm{NO}_{3}^{-}$, mais estáveis que a amônia (Fenn et al., 1981).

A aplicação conjunta de sais de elevada solubilidade de cátions $\mathrm{Ca}^{2+}$ e $\mathrm{Mg}^{2+}$ e fontes de $\mathrm{N}-\mathrm{NH}_{4}{ }^{+}$reduzem as perdas de amônia por volatilização em ambientes com a disponibilidade de água reduzida (Evangelou, 1990). O caráter solúvel desses sais é determinado pelas ligações iônicas que, por serem fracas, não completam as exigências de elétrons dos cátions. Para haver a neutralização total das cargas, na condição disponibilidade de água reduzida, estes cátions promovem o compartilhamento dos elétrons da amônia através de pontes de hidrogênio com a água de hidratação desses sais. Como conseqüência da protonação da amônia a íon $\mathrm{NH}_{4}{ }^{+}$, este é adsorvido ao par iônico salino carregado negativamente. Da mesma forma, a adsorção do $\mathrm{NH}_{4}{ }^{+}$aos colóides pode ocorrer em condições de reduzida disponibilidade de água, porque os mesmos cátions, quando adsorvidos à superfície coloidal formam complexos de esfera externa (Sposito, 1984), que da mesma forma que os pares iônicos, apresentam um caráter fraco.

A utilização de fertilizantes de sais de cátions monovalentes para redução das perdas de amônia por volatilização foi verificada por Fenn et al. (1982). O trabalho estabeleceu que, para as condições de solos ácidos, a substituição do $\mathrm{Ca}^{2+}$ por $\mathrm{K}^{+}$ou $\mathrm{NH}_{4}^{+}$nos sais empregados era possível, apesar da menor eficiência. No entanto, essa eficiência é crescente com o aumento da CTC e da quantidade de $\mathrm{Ca}^{2+}$ trocável dos solos e variável com o sal utilizado e a quantidade de $\mathrm{N}$ aplicada.

$\mathrm{O}$ uso do $\mathrm{KCl}$ como fertilizante aplicado conjuntamente com a uréia para reduzir as perdas de amônia por volatilização tem mostrado resultados positivos comprovados em literatura (Christianson et al., 1995; Fenn et al., 1990; Gameh et al., 1990; Rappaport \& Axley, 1984).

Outros estudos têm avaliado o efeito de fertilizantes fosfatados sobre as perdas de amônia por volatilização. A elevação da CTC ocasionada pela adsorção do fosfato foi uma das principais causas do efeito do fosfato monocálcico (superfosfato triplo) no trabalho de Sengik \& Kiehl (1995). Outro efeito dos fertilizantes fosfatados ocorre pelo poder acidificante dos produtos como o fosfato monoamônioMAP $\left(\mathrm{NH}_{4} \mathrm{H}_{2} \mathrm{PO}_{4}\right)$ (Sengik \& Kiehl, 1995).

Quando utiliza-se $\mathrm{KCl}$ aplicado à uréia, a complementação da mistura com fertilizante fosfatado pode alterar a eficiência do $\mathrm{KCl}$ no controle das perdas de amônia por volatilização. A aplicação de fosfato de cálcio (superfosfato triplo) ao $\mathrm{KCl}$ e à uréia pode aumentar o controle das perdas, mas a aplicação de fosfatos de K exibe a tendência de redução do efeito do $\mathrm{KCl}$ sobre as perdas, mostrando que o efeito é dependente da reação de dissociação do cátion acompanhante do ânion fosfato ser ácida ou 
alcalina (Fenn et al., 1990). Quando o cátion é o amônio, os trabalhos têm revelado a contribuição do fertilizante (MAP) na redução das perdas de amônia por volatilização, porque o amônio apresenta efeito acidificante (Fan \& Mackenzie, 1993; Rappaport \& Axley, 1984; Sengik \& Kiehl, 1995).

O controle efetivo das perdas de amônia por volatilização é dependente, não só da aplicação de aditivos em conjunto com as fonte de $\mathrm{N}$-amoniacal mas, também, da relação de aplicação entre o fertilizante amoniacal e o aditivo, seja fonte de $\mathrm{P}$ ou fonte de $\mathrm{K}$ (Fenn et al., 1990; Rappaport \& Axley, 1984; Sengik \& Kiehl, 1995).

O trabalho teve por objetivo avaliar os efeitos da aplicação de sais de $\mathrm{K}$ e de $\mathrm{P}$ às soluções de carbonato/bicarbonato de amônio e de aquamônia sobre a produção de material vegetal seco da parte aérea, a extração total de $\mathrm{N}$ e sobre a recuperação do $\mathrm{N}$ aplicado por soqueiras de cana-de-açúcar.

\section{MATERIAL E MÉTODOS}

O experimento foi conduzido ao ar livre, em área do Departamento de Solos e Nutrição de Plantas da ESALQ/USP, em Piracicaba, SP, utilizando-se vasos contendo $100 \mathrm{dm}^{3}$ de terra do horizonte Bt de um Podzólico Vermelho-Escuro Latossólico (Rhodic Kandiudox), textura argilosa (57,8\% de argila).

A terra peneirada, seca ao ar e acondicionada nos vasos apresentou, de acordo com a metodologia de Raij \& Quaggio (1983), as seguintes características químicas: $18,4 \mathrm{~g} \mathrm{~kg}^{-1}$ de M.O.; $\mathrm{pH}\left(\mathrm{CaCl}_{2} 0,01 \mathrm{~mol} \mathrm{~L}^{-1}\right)$ de 4,$55 ; 13 \mathrm{mg} \mathrm{kg}^{-1}$ de $\mathrm{P}$ (resina); 0,8, 22, 6,8, 29,3 e $59 \mathrm{mmol}_{\mathrm{c}} \mathrm{dm}^{-3}$ de $\mathrm{K}, \mathrm{Ca}, \mathrm{Mg}, \mathrm{H}+\mathrm{Al}$ e $\mathrm{T}$, respectivamente; e $\mathrm{V} \%$ igual a 50,3 . Foi aplicado e misturado ao volume total de terra, calcário calcinado dolomítico em quantidade necessária para a elevação da saturação por bases a 70\%, aplicando-se, a seguir, uma quantidade de água suficiente para se atingir a umidade do solo correspondente a $80 \%$ da capacidade de campo, mantida pela cobertura dos vasos com plástico durante 30 dias.

Soqueiras de cana-de-açúcar da variedade "RB72454" foram retiradas de uma área experimental, transplantadas para os vasos e cultivadas por noventa dias, em um estudo preliminar, finalizado com o corte da parte aérea das plantas. Após esse procedimento, iniciou-se este estudo nas unidades experimentais.
O experimento constituiu-se de um fatorial $2 \times 3$, disposto em um delineamento inteiramente casualizado, com 4 repetições. Os tratamentos, apresentados na TABELA 1, constaram de duas fontes líquidas de $\mathrm{N}$ (aquamônia-AA e carbonato/ bicarbonato de amônio-CA) que variaram em função da ausência de $\mathrm{K}$ e de $\mathrm{P}$ e presenças de $\mathrm{K}$ e PK, aplicados como $\mathrm{KCl}$ e fosfato monoamônioMAP $\left(\mathrm{NH}_{4} \mathrm{H}_{2} \mathrm{PO}_{4}\right)$. Paralelamente ao ensaio, foram conduzidas 4 parcelas experimentais às quais aplicaram-se apenas os sais de $\mathrm{P} e$ de $\mathrm{K}$, utilizadas como testemunha para a obtenção do valor de $\mathrm{N}$ recuperado do fertilizante (NRF).

Para fornecer as quantidades equivalentes dos macronutrientes primários a todos os tratamentos, soluções complementares foram fornecidas em pontos diferentes aos da aplicação da solução tratamento, para se evitar interferências nos resultados. Contudo, mantiveramse as distâncias das soqueiras e profundidades de aplicação equivalentes. As quantidades de $P$ e $\mathrm{K}$ fornecidas a cada tratamento por essas soluções apresentam-se na TABELA 2.

As soluções foram aplicadas a uma distância de $15 \mathrm{~cm}$ das soqueiras, em subsuperfície. A aplicação foi realizada em profundidade para evitar a volatilização da amônia. A aplicação de fertilizantes amoniacais é recomendada a uma profundidade mínima de $5 \mathrm{~cm}$ e, no caso da aquamônia, $15 \mathrm{~cm}$. Contudo, a maior profundidade de aplicação acarreta maiores danos ao sistema radicular das soqueiras, razão pela qual determinou-se a aplicação de todas as soluções a $5 \mathrm{~cm}$ de profundidade. A quantidade de $\mathrm{N}$ total aplicado (NTA) em cada unidade experimental (UE), independentemente das soluções utilizadas, foi de $3,5 \mathrm{~g} \mathrm{~N}$. Todas as unidades experimentais receberam, ainda, $1,2 \mathrm{~g} \mathrm{P}_{2} \mathrm{O}_{5}$ e $4,4 \mathrm{~g} \mathrm{~K}_{2} \mathrm{O}$. Não foi aplicado $N$ às UE referentes ao tratamento adicional PK.

As soqueiras de cada UE foram cultivadas durante noventa dias. Após esse período, as plantas foram cortadas ao nível do solo e a parte aérea separada em folhas e colmo. Todo o material foi lavado e seco em estufa de circulação forçada de ar a $65-70^{\circ} \mathrm{C}$ para a determinação da massa de material seco da parte aérea (g por UE). Determinaram-se os teores de $\mathrm{N}$ total das folhas e dos colmos pelo método semi-micro-Kjeldahl (Sarruge e Haag, 1974). A apresentação dos resultados na formas de $\mathrm{N}$ total extraído (NTE) pela parte aérea em $\mathrm{g}$ por UE, foi feita pelo cálculo: $\left[10^{-3} \times\left(\mathrm{g} \mathrm{kg}^{-1} \mathrm{de}\right.\right.$ 
TABELA 1 - Tratamentos, quantidades de nutrientes fornecidas por soluções de tratamento e o volume aplicado.

\begin{tabular}{|c|c|c|c|c|c|}
\hline Tratamento & $\mathrm{N}$ & $\mathrm{P}_{2} \mathrm{O}_{5}$ & $\mathrm{~K}_{2} \mathrm{O}$ & Composição das fórmulas & $\begin{array}{c}\text { Volume aplicado } \\
\text { por vaso }\end{array}$ \\
\hline \multicolumn{5}{|c|}{---- g por UE ---- } & $\mathrm{cm}^{3}$ \\
\hline$A A^{(1)}$ & 3,5 & - & - & $144,6 \mathrm{~g} \mathrm{AA}+239,2 \mathrm{~g}$ água & 54,6 \\
\hline$A A+K$ & 3,5 & - & 4,0 & $\begin{array}{l}680,4 \mathrm{~g} \mathrm{AA}+179,0 \mathrm{~g} \text { água }+1080,1 \mathrm{~g} \text { sol. } \\
\mathrm{KCl}\left(14 \% \mathrm{~K}_{0} \mathrm{O}\right)\end{array}$ & 52,2 \\
\hline$A A+P+K$ & 3,5 & 1,1 & 3,6 & $\begin{array}{l}271,8 \mathrm{~g} \mathrm{AA}+328,3 \mathrm{~g} \text { água }+32,0 \mathrm{gAP}^{(2)} \\
+84,0 \mathrm{~g} \mathrm{KCl}+2,4 \mathrm{~g} \mathrm{H}_{2} \mathrm{SO}_{4}\end{array}$ & 51,5 \\
\hline $\mathrm{CA}^{(3)}$ & 3,5 & - & - & $722,1 \mathrm{~g} \mathrm{AA}+938,1 \mathrm{~g}$ água $+237,2 \mathrm{~g} \mathrm{CO}_{2}$ & 48,3 \\
\hline$C A+K$ & 3,5 & - & 4,4 & $\begin{array}{l}676,9 \mathrm{~g} \mathrm{AA}+177,1 \mathrm{~g} \mathrm{CO}_{2}+1080,8 \mathrm{~g} \mathrm{sol} \\
\mathrm{KCl}\left(14 \% \mathrm{~K}_{2} \mathrm{O}\right)\end{array}$ & 56,7 \\
\hline$C A+P+K$ & 3,5 & 1,2 & 3,5 & $\begin{array}{l}670 \mathrm{~g} \mathrm{AA}+209,5 \mathrm{~g} \mathrm{CO}_{2}+210,2 \mathrm{~g} \mathrm{KCl}+ \\
80,0 \mathrm{~g} \mathrm{MAP}+610,8 \mathrm{~g} \text { água }\left(+\mathrm{H}_{2} \mathrm{SO}_{1}\right)\end{array}$ & 51,3 \\
\hline PK & - & 1,2 & 4,4 & $\begin{array}{l}31,43 \mathrm{~g} \mathrm{sol} . \mathrm{KCl}\left(14 \% \mathrm{~K}_{2} \mathrm{O}\right)+2,3 \mathrm{~g} \mathrm{H}_{3} \mathrm{PO}_{4} \\
\left(52 \% \mathrm{P}_{2} \mathrm{O}_{5}\right)\end{array}$ & 32,7 \\
\hline (Testemunha & & & & & \\
\hline
\end{tabular}

(1) Aquamônia; (2) Fosfato monoamônio; (3) Carbonato/bicarbonato de amônio.

TABELA 2 - Quantidades de $\mathrm{P}$ e de $\mathrm{K}$ fornecidas aos tratamentos por soluções complementares e o volume aplicado.

\begin{tabular}{|c|c|c|c|c|c|c|}
\hline \multirow[t]{2}{*}{ Tratamento } & \multirow[t]{2}{*}{$\mathrm{P}_{2} \mathrm{O}_{5}$} & \multirow[t]{2}{*}{$\mathrm{K}_{2} \mathrm{O}$} & \multicolumn{3}{|c|}{ Composição das fórmulas } & \multirow[t]{2}{*}{$\begin{array}{c}\text { Volume aplicado } \\
\text { por vaso }\end{array}$} \\
\hline & & & $\mathrm{H}_{3} \mathrm{PO}_{4}$ & $\mathrm{KCl}$ & Água & \\
\hline & \multicolumn{2}{|c|}{----- g por UE ----- } & \multicolumn{3}{|c|}{--------------- g --------------- } & $\mathrm{cm}^{3}$ \\
\hline $\mathrm{AA}^{(1)}$ & 1,2 & 4,4 & 2,3 & 7,3 & 50,0 & 58,6 \\
\hline$A A+K$ & 1,2 & 0,4 & 2,3 & 0,7 & 50,0 & 52,0 \\
\hline$A A+P+K$ & 0,1 & 0,8 & 0,2 & 1,4 & 50,0 & 51,5 \\
\hline $\mathrm{CA}^{(2)}$ & 1,2 & 4,4 & 2,3 & 7,3 & 50,0 & 58,6 \\
\hline$C A+K$ & 1,2 & - & 2,3 & - & 50,0 & 51,3 \\
\hline$C A+P+K$ & - & 0,9 & - & 1,5 & 50,0 & 51,5 \\
\hline
\end{tabular}

(1)Aquamônia; (2)Carbonato/bicarbonato de amônio

$\mathrm{N}_{\text {follha }} \times \mathrm{g}$ por UE M.S. .tolha $)+10^{-3} \times\left(\mathrm{g} \mathrm{kg}^{-1}\right.$ de $\mathrm{N}_{\text {colmo }}$ $x \mathrm{~g}$ por UE M.S. colmo )] e do $\mathrm{N}$ recuperado do fertilizante (NRF) em \%, utilizando-se a relação: $\left[10^{2} \times\left(\mathrm{NTE}_{\text {tratamento }}-\mathrm{NTE}_{\text {testemunha }}\right) \times \mathrm{NTA}^{-1}\right]$. Os resultados foram analisados estatisticamente através do programa SAS (SAS Institute, 1989) para a análise da variância e aplicação do teste Tukey a $5 \%$ de significância.

\section{RESULTADOS E DISCUSSÃO}

A produção de material seco da parte aérea, pelas soqueiras de cana-de-açúcar da variedade "RB72454", foi significativamente maior quando a fonte de nitrogênio empregada foi o carbonato/bicarbonato de amônio (Figura 1). As produções obtidas foram de 280 e $308 \mathrm{~g}$ de material seco por UE com as fontes 
aquamônia e carbonato/bicarbonato de amônio, respectivamente.

A fonte alternativa para fornecimento de nitrogênio apresentou potencial viável para utilização na cultura da cana-de-açúcar, pois proporcionou aumentos de $10 \%$ na produção de material seco. O potencial agrícola de utilização do bicarbonato de amônio como fonte de nitrogênio também foi demonstrado em experimentos de campo com a cultura do arroz, principalmente para solos de reação ácida (Li \& Chen, 1980).

A diferença apresentada na produção de material seco da parte aérea pode, contudo, ter sido ocasionada por questões técnicas de aplicação dos fertilizantes. A aquamônia é um produto menos estável que o carbonato/bicarbonato de amônio, apresentando alta pressão de $\mathrm{NH}_{3}$, o que a torna mais suscetível as perdas de amônia por volatilização. A aplicação das soluções ocorreu a $5 \mathrm{~cm}$ de profundidade para evitar o rompimento excessivo de raízes, quando o recomendado para a aquamônia é $15 \mathrm{~cm}$, uma vez que o aumento da profundidade de aplicação dos fertilizantes amoniacais reduz a taxa de perda.

A presença dos sais $\mathrm{KCl}$ e $\mathrm{KCl}+\mathrm{MAP}$ junto às fontes de nitrogênio não apresentou efeito significativo sobre produção de material seco pela parte aérea. Este resultado demonstra que as soluções complementares de $\mathrm{P}$ e $\mathrm{K}$ (TABELA 2), aplicadas em outro ponto, auxiliaram a suprir estes nutrientes e não limitaram a produção de material seco. Apesar de não terem sido demonstrados efeitos significativos, a literatura relata a produção vegetal como um parâmetro utilizado para avaliação da eficiência da nutrição nitrogenada de fontes amoniacais em função do fornecimento conjunto de K, verificando-se, inclusive, aumentos na matéria seca produzida (Rappaport \& Axley, 1984).

As fontes não diferiram na quantidade de $\mathrm{N}$ total extraído (NTE) pelas soqueiras (Figura 1). Este fato ocorreu pelo efeito de concentração dos teores de $\mathrm{N}$ nos tecidos das plantas adubadas com aquamônia que apresentaram menor produção de material seco da parte aérea. Em média, as plantas das UE que receberam esta fonte apresentaram $7,81 \mathrm{~g} \mathrm{~kg}^{-1}$ de $\mathrm{N}$ na folha e $5,72 \mathrm{~g} \mathrm{~kg}^{-1}$ de $\mathrm{N}$ no colmo, ao passo que as plantas das UE que receberam carbonato/ bicarbonato de amônio apresentaram 7,76 g kg de $\mathrm{N}$ na folha e $5,57 \mathrm{~g} \mathrm{~kg}^{-1}$ de $\mathrm{N}$ no colmo. A maior produção de material seco da parte aérea pelas plantas adubadas com carbonato/bicarbonato de amônio garantiu, entretanto, a equivalência no NTE.

A aplicação de sais aos fertilizantes nitrogenados resultou em diferenças significativas entre o NTE pelas soqueiras (Figura 2), não sendo, porém, verificada significância para a interação fonte $x$ sais aplicados. As plantas fertilizadas por qualquer uma das duas fontes de $\mathrm{N}$ extraíram as quantidades médias de 2,$1 ; 2,2$ e $1,8 \mathrm{~g}$ de $\mathrm{N}$ por UE, para as soluções de $\mathrm{N}$, NK e NPK, respectivamente. A aplicação de sais de $\mathrm{K}$ e $\mathrm{PK}$ às fontes de $\mathrm{N}$ não promoveu efeitos significativos sobre o aproveitamento de $\mathrm{N}$ pela soqueira de cana-de-açúcar, quando comparados às soluções nitrogenadas aplicadas isoladamente.

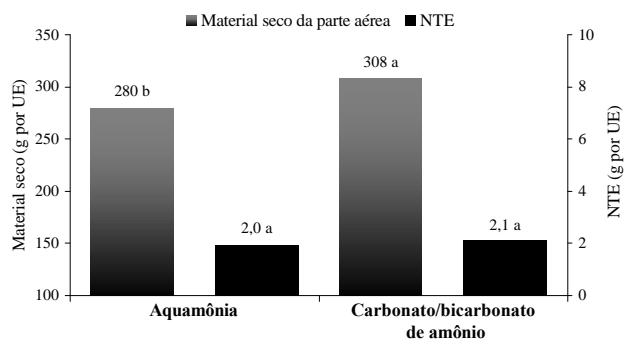

Figura 1 - Produção de material seco e nitrogênio total extraído (NTE) pela parte aérea de soqueira de cana-de-açúcar RB72454 aos 90 dias. (Médias seguidas de letras distintas diferem a $5 \%$ pelo teste Tukey).

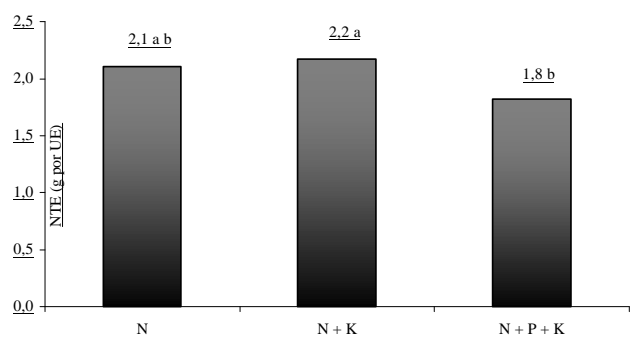

Figura 2 - Nitrogênio total extraído (NTE) pela parte aérea de soqueira de cana-deaçúcar RB72454 aos 90 dias, quando aplicado aquamônia ou carbonato/ bicarbonato de amônio. (Médias seguidas de letras distintas diferem a $5 \%$ pelo teste Tukey). 
Dos vários aspectos que determinam o aproveitamento do $\mathrm{N}$ pelas culturas, a quantidade do $\mathrm{N}$ do fertilizante aplicado e que permanece disponível às plantas é um fator importante, que têm sido relacionado à utilização conjunta do $\mathrm{KCl}$. Os resultados do trabalho não confirmaram este efeito, porém, - $\mathrm{KCl}$, quando aplicado em conjunto com a uréia ou fertilizante amoniacal, promove a redução das perdas de amônia por volatilização, pelo abaixamento do $\mathrm{pH}$ do solo no ponto de aplicação e, possivelmente, pela formação paralela de $\mathrm{NH}_{4} \mathrm{Cl}$ (Fenn et al., 1982; Rappaport \& Axley, 1984; Fenn et al., 1990; Gameh et al., 1990; Christianson et al., 1995), resultando numa quantidade maior de $\mathrm{N}$ do fertilizante disponível para a absorção pelas plantas (Rappaport \& Axley, 1984).

A utilização do fertilizante MAP $\left(\mathrm{NH}_{4} \mathrm{H}_{2} \mathrm{PO}_{4}\right)$ como fonte de $\mathrm{P}$ adicionada às soluções das fontes de $\mathrm{N}+\mathrm{KCl}$ proporcionaram as menores quantidades de NTE. Estes valores foram significativamente menores que 0 NTE da soluções de NK, indicando efeito negativo do MAP. O cátion acompanhante pode determinar o efeito do aditivo fosfatado, pela condição da reação de dissociação ser ácida ou alcalina (Fenn et al., 1990). O MAP apresenta efeito acidificante, o que justifica seu emprego como aditivo aos fertilizantes amoniacais e contraria 0 resultado obtido. Contudo, este efeito é determinado pela quantidade de fósforo utilizado em relação ao total de $\mathrm{N}$ aplicado (Sengik \& Kiehl, 1995).

Efeito equivalente da aplicação de sais aos fertilizantes nitrogenados foi verificado sobre a recuperação do $\mathrm{N}$ aplicado como fertilizante (NRF) pela soqueira. Os valores de NRF obtidos para a utilização das soluções de N, NK, NPK foram 39; 41 e 31\%, respectivamente (Figura 3). A aplicação de $\mathrm{KCl}$ proporcionou recuperação equivalente à aplicação do fertilizante nitrogenado isoladamente, mas a mistura de $\mathrm{MAP}+\mathrm{KCl}$ às fontes de $\mathrm{N}$ reduziram a NRF significativamente em relação à aplicação de $\mathrm{N}+\mathrm{KCl}$.

Li \& Chen (1980) obtiveram valores de recuperação do $\mathrm{N}$ pela cultura do arroz de 22,37 e $65 \%$ para o bicarbonato de amônio, na forma de pastilhas ou grânulos, aplicado em superfície, incorporado superficialmente ou em profundidade. O valor de NRF obtido pela incorporação superficial foi semelhante aos valores desse estudo, indicando que mesmo na forma líquida, um

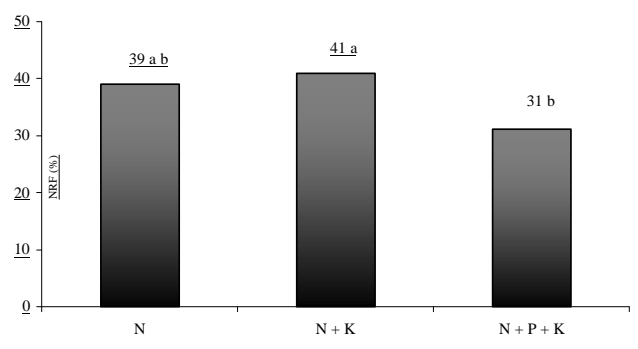

Figura 3 - Nitrogênio recuperado do fertilizante (NRF) pela parte aérea de soqueira de cana-de-açúcar RB72454 aos 90 dias, quando aplicado aquamônia ou carbonato/bicarbonato de amônio. (Médias seguidas de letras distintas diferem a $5 \%$ pelo teste Tukey).

dos fatores determinantes do aproveitamento do $\mathrm{N}$ pelas culturas é o critério de aplicação e incorporação dos fertilizantes nitrogenados.

As relações molares N:K e N:P:K nas soluções utilizadas neste trabalho foram 1:1 e $6,7: 1,0: 7,0 ;$ respectivamente. $O$ uso da relação $1: 1$ de $\mathrm{N}$ e $\mathrm{K}$ têm mostrado efeitos benéficos sobre as perdas de amônia por volatilização e sobre 0 aproveitamento do $\mathrm{N}$ pelas plantas, sendo o efeito adicional de relações mais elevadas em $\mathrm{K}$ não significativo (Rappaport \& Axley, 1984). A quantidade de fósforo utilizada, em relação ao total de $\mathrm{N}$ aplicado, foi inferior às demonstradas na literatura como positivas para a redução das perdas de amônia por volatilização. $\mathrm{Na}$ relação entre $\mathrm{N}$ e $P$ de 2:1 verificaram-se os efeitos benéficos da aplicação conjunta dos nutrientes (Rappaport \& Axley, 1984), ocorrendo, ainda, crescentes respostas com a aplicação mais elevada de fósforo, nas formas de fosfato de amônio (Sengik \& Kiehl, 1995) e de fosfato de cálcio (Fenn et al., 1990).

\section{CONCLUSÕES}

As soluções de carbonato/bicarbonato de amônio foram mais eficientes que as de aquamônia na produção de material seco da parte aérea da soqueira de cana-deaçúcar.

A adição de $\mathrm{KCl}$ e $\mathrm{NH}_{4} \mathrm{H}_{2} \mathrm{PO}_{4}$ às soluções de $\mathrm{N}$ não interferiram na extração e na eficiência de recuperação do $\mathrm{N}$ do fertilizante pela soqueira, para as relações $\mathrm{N}: \mathrm{K}$ e $\mathrm{N}: \mathrm{P}: \mathrm{K}$ avaliadas. 


\section{REFERÊNCIAS BIBLIOGRÁFICAS}

CHRISTIANSON, C.B.; CARMONA, G.; KLEIN, M.O.; HOWARD, R.G. Impact on ammonia volatilization losses of mixing $\mathrm{KCl}$ of high $\mathrm{pH}$ with urea. Fertilizer Research, v.40, n.2, p.89-92, 1995.

Du PLESSIS, M.C.F.; KROONTJE, W. The effect of carbon dioxide on chemisorption of ammonia by base-saturated clays. Soil Science Society of America Journal, v.30, n.6, p.693-696, 1966.

EVANGELOU, V.P. Regulation mechanisms and field implications of ammonia bonding with various crystalline salts. Soil Science Society of America Journal, v.54, n.2, p.394-398, 1990.

FAN, M.X.; MACKENZIE, A.F. Urea and phosphate interactions in fertilizer microsites: ammonia volatilization and $\mathrm{pH}$ changes. Soil Science Society of America Journal, v.57, n.3, p.839-845, 1993.

FENN, L.B.; MIYAMOTO, S. Ammonia loss and associated reactions of urea in calcareous soils. Soil Science Society of America Journal, v.45, n.3, p.537-540, 1981

FENN, L.B.; TAYLOR, R.M.; MATOCHA, J.E. Ammonia losses from surface-applied nitrogen fertilizer as controlled by soluble calcium and magnesium: general theory. Soil Science Society America Journal, v.45, n.4, p.777-781, 1981.

FENN, L.B.; MATOCHA, J.E.; WU, E. Substitution of ammonium and potassium for added calcium in reduction of ammonia loss from surface-applied urea. Soil Science Society of America Journal, v.46, n.3, p.771-776, 1982.

FENN, L.B.; TATUM, G.; HORST, G. Ammonia losses from surface-placed mixtures of ureacalcium-potassium salts in the presence of phosphorus. Fertilizer Research, v.21, n.3, p.125-131, 1990.
FUZATO, M.A.; GARCIA, M.V.D.; ROSSELL, C.E.V. Alternativa para o aproveitamento do $\mathrm{CO}_{2}$ gerado na fermentação alcoólica - Produção de bicarbonato de amônio, bicarbonato de sódio e soluções de sulfato de amônio. Boletim Técnico COPERSUCAR, v.43, p.48-51, 1988.

GAMEH, M.A.; ANGLE, J.S.; AXLEY, J.H. Effects of urea-potassium chloride and nitrogen transformations on ammonia volatilization from urea. Soil Science Society of America Journal, v.54, n.6, p.1768-1772, 1990.

LI, C.K.; CHEN, R.Y. Ammonium bicarbonate used as a nitrogen fertilizer in China. Fertilizer Research, v.1, p.125-136, 1980.

RAIJ, B. van; QUAGGIO, J.A. Métodos de análise de solo para fins de fertilidade. Campinas: IAC, 1983. 31p. (Boletim, 81).

RAPPAPORT, B. D.; AXLEY, J.H. Potassium chloride for improved urea fertilizer efficiency. Soil Science Society of America Journal, v.48, n.2, p.399-401, 1984.

SARRUGE, J.R.; HAAG, H.P. Análises químicas em plantas. Piracicaba: ESALQ, Departamento de Química, 1974. 56p.

SAS INSTITUTE. SAS/STAT user's guide: version 6. 4.ed. Cary: Statistical Analysis System Institute, 1989. v.2, 846p.

SENGIK, E; KIEHL, J.C. Controle da volatilização de amônia em terra tratada com uréia e turfa pelo emprego de sais inorgânicos. Revista Brasileira de Ciência do Solo, v.19, n.3, p.455-461, 1995.

SPOSITO, G. Inorganic and organic solute adsorption in soils. In: SPOSITO, G. The surface chemistry of soils. New York: Oxford University Press, 1984. cap.4, p.113-153.

TERMAN, G.L. Volatilization losses of nitrogen as ammonia from surface-applied fertilizers, organic amendments, and crop residues. Advances in Agronomy, v.31, p.189-223, 1979.

Recebido para publicação em 13.10.98 Aceito para publicação em 12.08.99 